\title{
Does Reactive Adaptation Exist? Using the Ecosystem Service Governance Approach to Evaluate Post-Drought Rural Food Security in Kenya
}

\author{
Grace W. Ngaruiya \\ University of Hamburg, Department of Geosciences, Climate Change and Security Research Group, Hamburg, \\ Germany \\ Email: ngaruiyag@gmail.com
}

Received 16 March 2014; revised 15 April 2014; accepted 13 May 2014

Copyright (C) 2014 by author and Scientific Research Publishing Inc.

This work is licensed under the Creative Commons Attribution International License (CC BY).

http://creativecommons.org/licenses/by/4.0/

c) (i) Open Access

\begin{abstract}
Controversial climate change studies purport that predicted food insecurity and resource scarcity will intensify resource conflicts in developing nations. This belief is based on a prevalent assumption that African agricultural production systems are rigid and that their respective governments lack comprehensive adaptation ability. Therefore, I investigate whether and how effective postdrought adaptation activity is sustaining food production and livelihoods at Loitoktok district in Kenya. This study uses the theoretical three-step ecosystem service governance approach that analyzes both natural resources attributes and relational data. Results confirm a substantial decline in productivity and huge monetary losses in the agricultural sector of Loitoktok following the 2009 drought. Post-drought analysis reveals high diversification in crops and livestock that are drought-tolerant, fast maturing and high income generating such as camels, rabbits and dairy goats, horticultural and fruit production that sustain food security, income and local livelihoods. These reactive adaptation activities originate from an active public-private cooperation that promotes knowledge exchange among Loitoktok stakeholders. This cooperation is also seen in the efficient resource conflict resolution network. In conclusion, rural communities seem to be efficiently adapting to changing environmental conditions but require more financial and technical support from the government. Unfortunately, appraisal of national planned adaptation reveals effort-duplication that may divert much needed adaptation funds from being invested in research projects with multiple benefits to Kenyan food producers.
\end{abstract}

\section{Keywords}

Climate Adaptation, Drought Impacts, Food Security, Knowledge Brokers, Social Networks, Kenya

How to cite this paper: Ngaruiya, G.W. (2014) Does Reactive Adaptation Exist? Using the Ecosystem Service Governance Approach to Evaluate Post-Drought Rural Food Security in Kenya. Natural Resources, 5, 392-407. 


\section{Introduction}

Ecosystem services are the benefits obtained from nature and are divided into four main categories; provisioning, regulating, supporting, and cultural services [1]. This study centres on provisioning ecosystem services which are defined as raw products such as food, fuel, fibre, fresh water, bio-chemicals and genetic resources that are harvested from nature. In particular, the study is based on food products obtained from plants and animals under subsistence agricultural supervision. Food provision as an ecosystem service clearly confirms a vital link between the environment and rural livelihoods through two main aspects. First, subsistence agriculture is widely endorsed by sub-Saharan governments as it creates food security especially among people who are in constant need of food aid and live in arid and semi-arid areas in Africa [2]. Second, rural food security systems generate income through diverse livelihoods of smallholder farmers, forest dwellers, pastoralists and artisanal fisher folk [3].

According to Abdou et al. [4], climate change will lead to a 50\% drop in agricultural production in Africa by 2030 via affecting rainfall, temperature and water availability in vulnerable areas. More explicitly, climate change will affect crop yields through frequent drought episodes, increased plant diseases, maturing period change and shifts in crop climates. It will affect livestock production though change in quantity and quality of fodder, heat stress, livestock diseases, water availability and loss of indigenous genetic biodiversity [5]. These consequences also have adverse effects on net farm revenues of crop and livestock farming systems to significantly upset economic growth, and worsen food insecurity. Moreover, the change projected will have consequences that extend far beyond agriculture as there are very real dangers that changed climate patterns will become drivers for conflict [6]-[8]. This popular "escalated" conflict scenario is controversial as some scientists think that many of these studies are unrealistically conducted [9] and are based on the negative assumption that African agricultural production systems are too rigid and will not change against prevailing climate stress [10]. Müller [10] found that 16 out 21 quantitative assessments indicated an increase in agricultural productivity under climate change in Africa. But he also stated that opportunities to limit negative impacts on African agriculture and enhance productivity need to be seized. These opportunities are collectively termed as adaptation-defined as the change in processes, practices, and structures that moderate potential damages from impacts of climate change or promote beneficial opportunities associated with climate change [11]. Though many forms of adaptation exist [12], this study focuses on two specific types:

a) Reactive adaptation refers to specific changes by an individual that are informed by direct negative climatic experience and which cause resources to be targeted to known risks to alleviate negative impacts once they have occurred.

b) Planned adaptation is executed mainly by governments and takes place prior to forecast events. In Kenya, planned adaptation is guided by the National Climate Change Response Strategy (NCCRS) developed by the Ministry of Environment in 2010 [13].

Documentation on adaptation activity especially from rural regions is very limited. Handmer et al., [14] posit that poorer regions will have difficulty adapting to climate change since they lack comprehensive technical and financial ability. Hence, there is a need to investigate whether and how rural adaptation activities have been implemented successfully in Kenya. This study seeks to contribute to the climate, livelihoods \& conflicts discourse by evaluating how rural communities have sustained food production despite increasing drought incidences in Kenya. Loitoktok district was selected as a practical case study because of its growing subsistence agricultural sector that is characteristic of a typical rural location in Kenya as well as sub-Saharan Africa.

This study applies the ecosystem service governance approach that incorporates monetary valuation of food production as an ecosystem service, climate governance and social network analysis to evaluate the adaptation process in relation to rural network structure [15]. The study objectives are, a) analyse agricultural production trends alongside drought occurrences to determine adaptation (if any and from who) embraced by a rural community and b) compare reactive adaptation against planned adaptation measures by the government. The guiding question is-has the rural social network structure facilitated food producers to adapt to the changing climatic conditions? Presumably, every community formulates certain economic survival strategies to maintain their food security and livelihoods despite changing environmental conditions. Thus, documentation of this information can help identify loopholes or additional measures to be integrated into planned adaptation for successful sustainable rural economic development.

In the following sections, the paper describes the study area and the ecosystem service governance approach, followed by the results from the approach and a discussion based on the study objectives. It concludes with a summary of the key findings on adaptation among rural food producers. 


\section{Methodology}

\subsection{Study Area}

Loitoktok is located at the southern tip of the former Rift Valley province and borders the Republic of Tanzania to the West (Figure 1). In terms of government administration, it is part of Kajiado County and is divided into six divisions, 16 locations and 31 sub-locations [16]. There are two key rainfall seasons in the area, i.e. heavy rains in October to December and light rains from March to May. The rainfall is not equally distributed because of the presence of Mt. Kilimanjaro at the border of the district to Tanzania that causes the lowest elevation to receive about $500 \mathrm{~mm}$ while the mountain slopes record an average of $1250 \mathrm{~mm}$. Similarly, temperature varies with altitude from as low as $10^{\circ} \mathrm{C}$ on the eastern slopes of Mt. Kilimanjaro to a mean maximum of about $30^{\circ} \mathrm{C}$ around Lake Amboseli.

The district covers a total area of $6356.30 \mathrm{~km}^{2}$ of which $7.66 \mathrm{~km}^{2}$ is forested, $837 \mathrm{~km}^{2}$ contains the parks and reserves (protected area), $4131.6 \mathrm{~km}^{2}$ is categorized as arable land, while urban settlements take up $410.2 \mathrm{~km}^{2}$ [16]. Loitoktok is categorized among the arid and semi-arid districts in Kenya but in the last decade most of the woodland areas have been converted to marginal crop farming areas, the swamps into irrigated land and grassland to bushlands by overgrazing and overstocking [17]. The population is estimated at 171,520 persons [16] who have stimulated land subdivision and fast economic growth.

Economic growth is mainly through increase in agriculture that has been observed through two actions. First, it is estimated that $71 \%$ of all herders in Kajiado county have attempted crop cultivation due to declining profitability from pastoralism following persistent droughts, shrinking land for pasture, increasing costs of treating and maintaining cattle and lack of better markets for beef products [18]. Second, people from neighbouring congested central highlands are migrating to Loitoktok district to cultivate the fertile and relatively well-watered slopes of Mt. Kilimanjaro and other hills [17]. The immigrant farmers focus on horticultural produce (such as Karella (Momordica charantia), Dolichos (Lablab purpureus), Ravaya (Solanum melongena) and Okra (Abelmoschus esculentus) targeting Indian markets.

\section{Land-use and vegetation cover of Loitoktok}

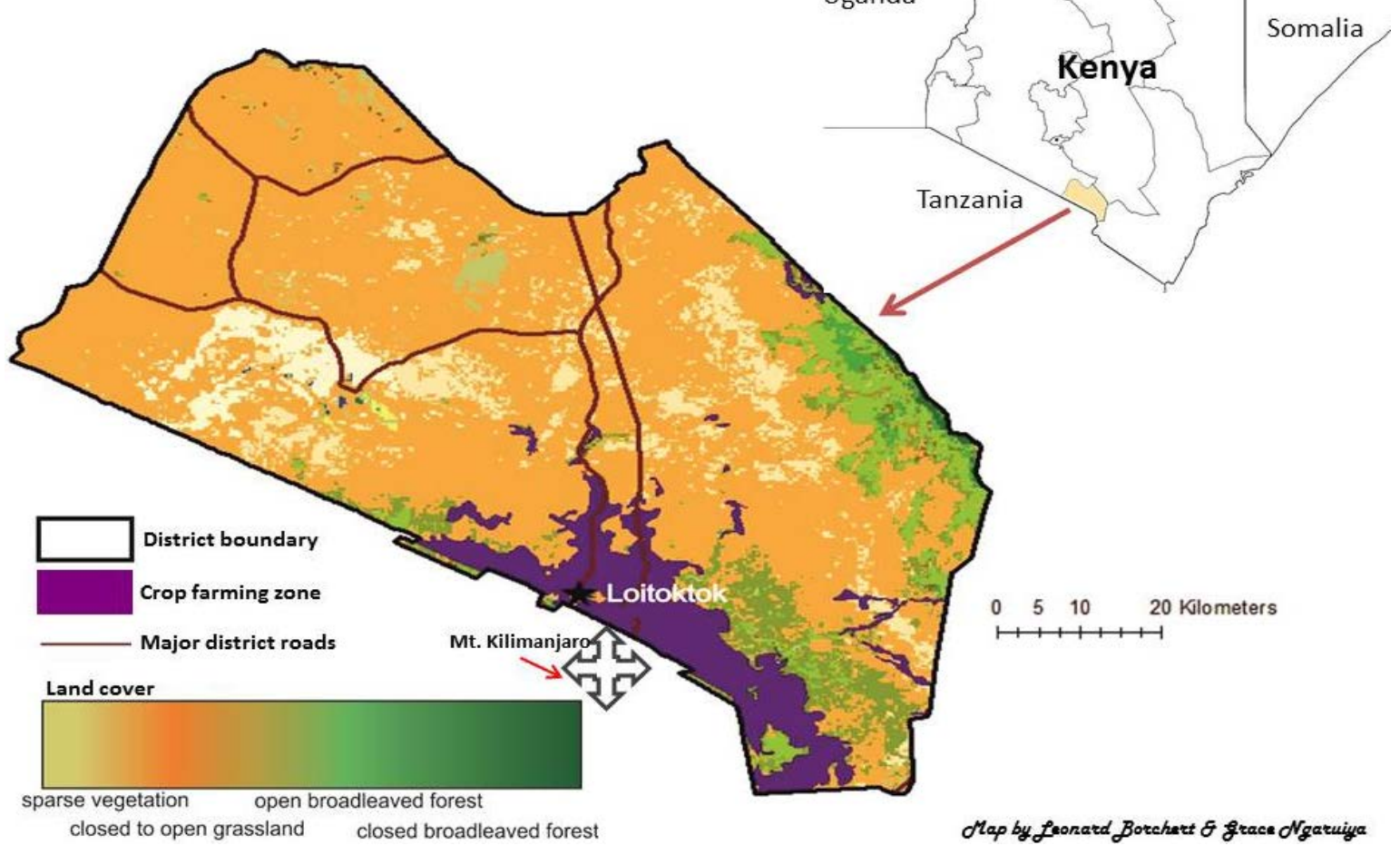

Figure 1. Location of Loitoktok district in Kenya and its proximity to Mt. Kilimanjaro. 


\subsection{Ecosystem Service Governance Approach}

Ernstson et al. [19] defined governance as the structures and processes by which collective action among diverse social actors (state, private, and civil society) is coordinated towards upholding certain publicly held values and resources. However, identifying stakeholders and more so identifying diverse stakeholders in an ecosystem scenario is not such a straightforward process [20]. Thus, current research in resource governance advocates for the study of social relationships to enhance local environmental outcomes [21] [22]. One of these governance approaches is the ecosystem service governance (ESG) approach that incorporates social network analysis, monetary valuation of food ecosystem services and climate governance into a single analytical natural resource governance framework [15]. The uniqueness of ESG is that it uses social network structure to understand resource governance and in a similar manner, this study analyses the food production network structure to understand the rural adaptation process. The analysis follows three main phases of the framework, namely: 1) Valuation of ecosystem services, in this case-monetary valuation of food provision which is done using market prices. 2) Resource-determinates that influence food production i.e. implemented climate adaptation and resource conflict resolution actions. 3) Social network analysis to diagnose network cohesion and identify scale-crossing brokers involved in the community.

\subsubsection{Monetary Valuation of Food Production}

Valuation techniques give monetary values to ecosystem services as a common medium for assessing the various benefits provided by ecosystems during a cost-benefit scenario [1]. The monetary value of crops and livestock in Loitoktok district was calculated using the 2013 base exchange rate (\$ 1= KES. 85), as follows:

a) The district agricultural office facilitated collection of data (2007-2011) of the yearly production rates, coverage and production rates for subsistence, fruit crops and the horticultural crops. Thereafter economic valuation of crops was calculated using documented yearly market prices.

b) The district livestock office provided data (2009 to 2011) of the numbers, breeds and types of livestock, livestock trade trends, costs of livestock products. The monetary value of livestock population was calculated using current market prices for live animals.

c) Valuation of honey was done using the two-step formula below:

(i) To estimate the total quantity of honey harvested per hive.

$$
\text { Honey }_{\mathrm{Kg}}=H \times 0.8 \times 11 \mathrm{Kg} \times 3
$$

where:

$H=$ Number of hives, $0.8=$ Hive occupation rate, $11 \mathrm{~kg}=$ Estimated yield per hive per harvest,

$3=$ Harvests possible per hive per year.

(ii) To get monetary value of honey in dollars.

$$
\text { Honey }_{\$}=\text { Honey }_{\mathrm{Kg}} \times \frac{150}{85}
$$

where:

$1 \mathrm{Kg}$ of crude honey $=$ KES 150.00 .

\subsubsection{Resource Determinates}

a) Climate adaptation measures

A semi-structured questionnaire collected information about climate change threats on food productivity, adaptation strategies and drawbacks to adaptation.

b) Resource conflict resolution

The same questionnaire also queried the causes of conflict, trends, underlying drivers (political or socioeconomic) and resolution stakeholders in the agricultural sector.

\subsubsection{Social Network Analysis}

A questionnaire collected network data using the saturation sampling technique. This method was selected because the study network was small and allowed for detailed and complete analyses of each and every network location [23]. Thus, a respondent was asked to name a maximum of five actors they have collaborations in terms of financial support, research \& training and project implementation to enhance food production. This actors' 
list was compiled and where possible, mentioned actors were located and asked about their partners in resource governance, this went on until no new actors were mentioned in the community.

The subsequent data was analysed for

a) Density values using

$$
d_{i}=\frac{L}{n(n-1) / 2}
$$

where:

$n=$ number of actors connected to actor $I$;

$L=$ number of lines between the actors.

b) Centralization values using

$$
C_{D}(i)=\sum_{j=1}^{n} x_{i j}=\sum_{i=1}^{n} x_{j i}
$$

where:

$x_{i j}=$ the sum of all ties from actor $i$ to actor $j$;

$n=$ the number of actors in the network.

c) Structural holes using

$$
C_{B}(k)=\sum_{i \neq j \neq k} \frac{\partial_{i k j}}{\partial_{i j}}
$$

where:

$\partial_{i k j}=$ number of paths linking actors $i$ and $j$ that pass through actor $k$;

$\partial_{i j}=$ number of paths linking actor $i$ and $j$.

Density and centrality values are used to indicate the level of cohesion in social networks. While structural holes are virtual empty holes in social networks that occur when actors with potential collaboration have no linkage between them and thus do not enjoy certain mutual benefits. These holes are sealed by actors labelled as knowledge brokers who actively create links between actors in the network. The data was visualised as a sociograph using NetDraw ${ }^{\mathrm{TM}}$ that efficiently illustrates the actual situation at the grassroots [24].

\section{Results}

Field data was collected between March-May and October-December 2012 in Loitoktok district.

\subsection{Monetary Vallue of Food Production}

a) Crops

Crops are classified into subsistence crops such as maize (Zea mays) and beans (Phaseolus vulgaris) for local consumption, horticultural and fruits crops that are grown for external markets. Fruits include oranges (Citrus spp.), avocadoes (Persea americana), mangoes (Mangifera indica), bananas (Musa spp.) and pawpaw's (Carica papaya). Crop production was valued at \$ 400 million/yr and comprised of $98.53 \%$ subsistence crops, $1.4 \%$ horticultural and $0.07 \%$ fruit crops (Table 1). The results also reveal the effect of the 2009 drought episode on crop

\begin{tabular}{|c|c|c|c|c|c|c|}
\hline \multicolumn{7}{|c|}{ Estimated annual performance of crop farming in Loitoktok district } \\
\hline \multirow{2}{*}{ Crops } & \multirow{2}{*}{$\begin{array}{c}\text { Total } \\
\text { coverage(Ha) }\end{array}$} & \multirow{2}{*}{$\begin{array}{l}\text { Av. production } \\
\text { (T/yr) }\end{array}$} & \multirow{2}{*}{$\begin{array}{l}\text { Gross value KES/yr } \\
\text { (million) }\end{array}$} & \multirow{2}{*}{$\begin{array}{l}\text { Gross value } \\
\$ / y r \text { (million) }\end{array}$} & \multicolumn{2}{|c|}{ Drought impacts in 2009} \\
\hline & & & & & Monetary value & Productivity \\
\hline Subsistence & 68614.37 & 919435.41 & 33523.00 & 394.39 & $-69.2 \%$ & $-68.5 \%$ \\
\hline Horticultural & 1171.20 & 23884.00 & 475.15 & 5.59 & $0.13 \%$ & $-52.2 \%$ \\
\hline Fruit & 117.00 & 1426.25 & 24.25 & 0.28 & $82.1 \%$ & $94.4 \%$ \\
\hline
\end{tabular}

Table 1. A summary of the crop coverage, production rates and monetary values in Loitoktok. The table also shows the estimated monetary and production impacts from the 2009 drought. 
yields and incomes whereby subsistence farmers suffered 69.2\% (\$330 million) loss in income due to a loss of $68.5 \%$ in production especially maize and beans. Similarly, harvest of horticultural crops fell by $52 \%$ but since these crops are traded in external affluent markets, the prices increased marginally to give farmers some income despite the low yields. The type of fruits planted have deep root-systems to survive drought episodes, thus fruit farmers' reaped a bumper harvest (94.4\%) and the subsequent demand-supply dynamics ensured super profits for the farmers. The prominent survival strategy of famers is planting subsistence and horticultural crops with fruit trees to provide additional incomes.

b) Livestock

In the district, milk (43 mL/yr.) is the highest produced item followed by beef, mutton, eggs, poultry and pork at 21,084 kgs, 10,422 kgs, 106,884 trays, 37,421 kgs and $2100 \mathrm{kgs}$ per year respectively (Figure 2). Honey production is slowly gaining ground as the community has acquired over 16,000 beehives (including 10,240 commercial hives) in order to engage in the lucrative sector.

Summation of livestock population gave an average annual figure of 723,382 individual animals in Loitoktok district. The estimated annual monetary value of livestock population and associated products is \$126.13 million (Table 2). Scrutiny of the livestock market reveals higher export values than import costs. Whereby exported livestock comprise of cattle, goats, sheep and hides that were valued at \$0.36 m, \$0.9 m and \$0.4 m in 2009 , 2010 and 2011 respectively. Livestock imports earned \$0.038 m (2009), \$0.052 (2010) and \$0.026 m (2011) for the district. Analysis shows a slight increase in 2010 of $34.8 \%$ that could be as a result of the community buying more dairy cattle and goats to restock their herds after drought decimated the livestock population in 2009. The community also bought Dorper sheep, Galla goats and camels that are indigenous to arid environment, have high demand by meat traders and also give good profits to the farmers.

\subsection{Resource Determinates}

The questionnaire was administered to 152 persons and also used to guide 15 group discussions in Loitoktok.

a) Climate adaptation measures

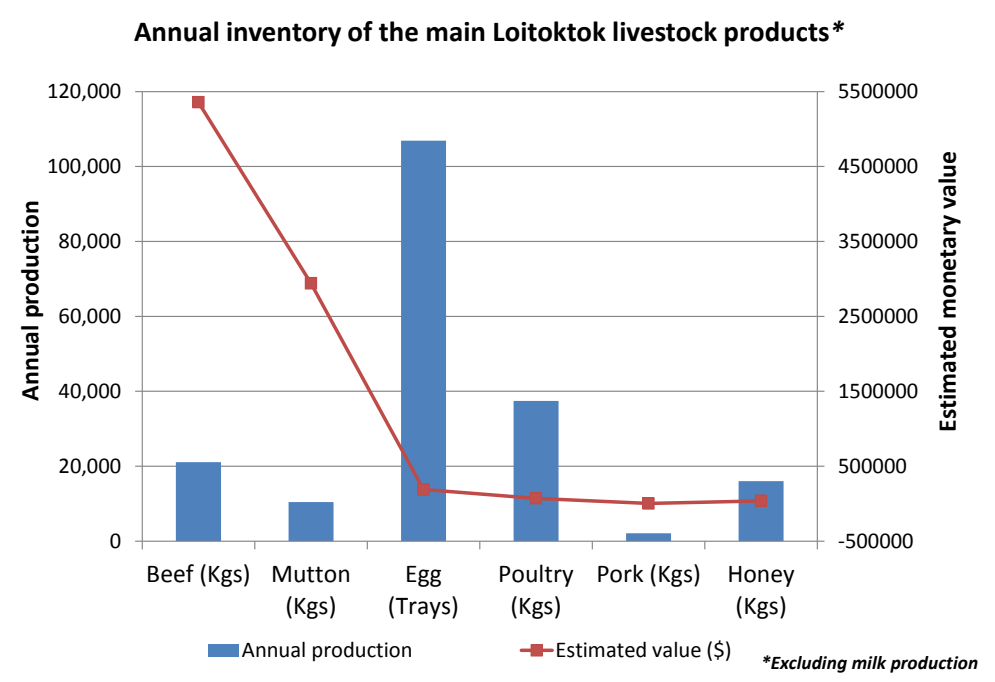

Figure 2. The production and monetary values of livestock in in Loitoktok.

Table 2. The estimated monetary values for the entire livestock sector (per annum) in Loitoktok.

\begin{tabular}{cccc}
\hline Livestock (2009-2011) & Categories & Gross value KES/year (million) & Gross value \$/year (million) \\
\hline \multirow{2}{*}{ Domestic } & Livestock population & 9120.71 & 107.30 \\
& Associated products & 1600.05 & 18.82 \\
\multirow{2}{*}{ Commercial } & Export & 47.21 & 0.55 \\
& Import & 3.27 & 0.03 \\
\hline
\end{tabular}


The climatic conditions that hinder successful food production according to respondents in Loitoktok are irregular precipitation (43\%), drought episodes (31\%), loss of biodiversity via degradation (23\%) and increased number of farmers and livestock keepers (3.4\%). However, further scrutiny of post-drought adaptation activities revealed specific measures in the crops and livestock sector sat Loitoktok.

Crop diversity demonstrated irregular productivity trends in the district (Figure 3). For example, chillies (Capsicum annuum) cultivation has diminished while the cultivation of kales and sorghum has increased. In 2010 (post-drought), there was a large increase in indigenous crops such as kale (Brassica oleracea), pigeon peas (Cajanus cajan) and sorghum (Sorghum bicolor), that have low water requirements but give high returns since demand is consistently high. Only dolichos and French beans, which are both horticultural crops and are sold in urban centers, had almost regular production rates. Maize, beans, tomatoes and onions were excluded from the graph because of their high production values but are discussed in other sections of this paper.

Traditional Maasai livestock used to be cattle (Bos primigenius), goats (Capra aegagrus hircus) and sheep (Ovis aries). However, increased interactions with other communities have seen introduction of dairy goats, pigs (Sus scrofa), donkeys (Equus asinus), camels (Camelus dromedarius), rabbits (Oryctolagus cuniculus) and even commercial bee-hives to supplement household income. In total, there are 17 different types of livestock comprising of diverse breeds in the district. There are also about 25 horses (Equus caballus) on private ranches in the district. Figure 4 shows the livestock profile of the district. The poultry section also includes turkeys (Mellea-

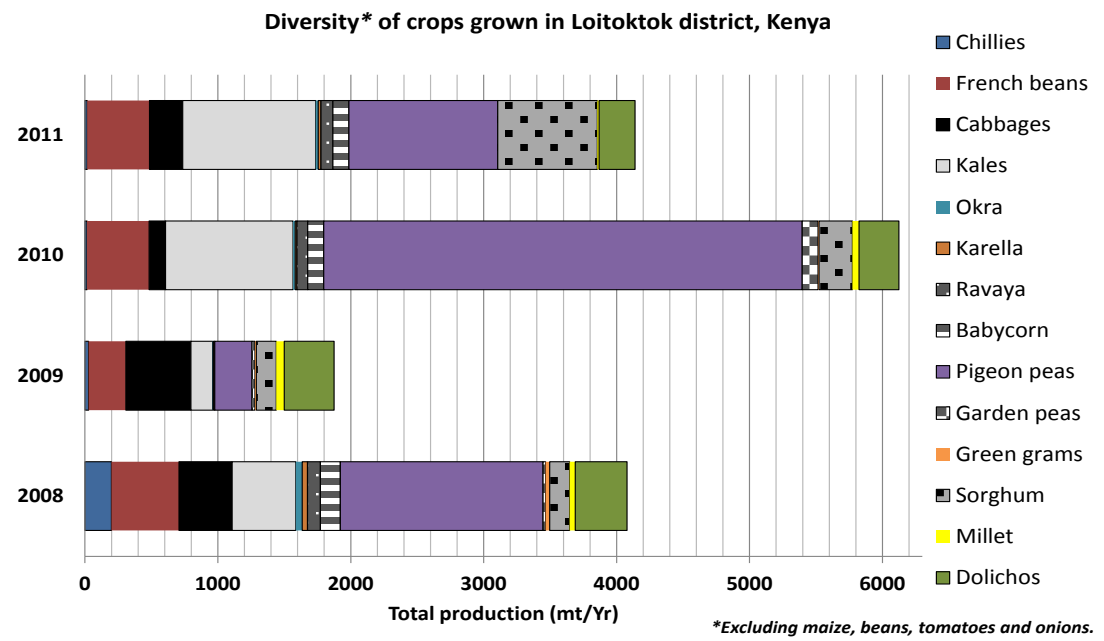

Figure 3. The diversity of crops grown and their production values in Loitoktok district.

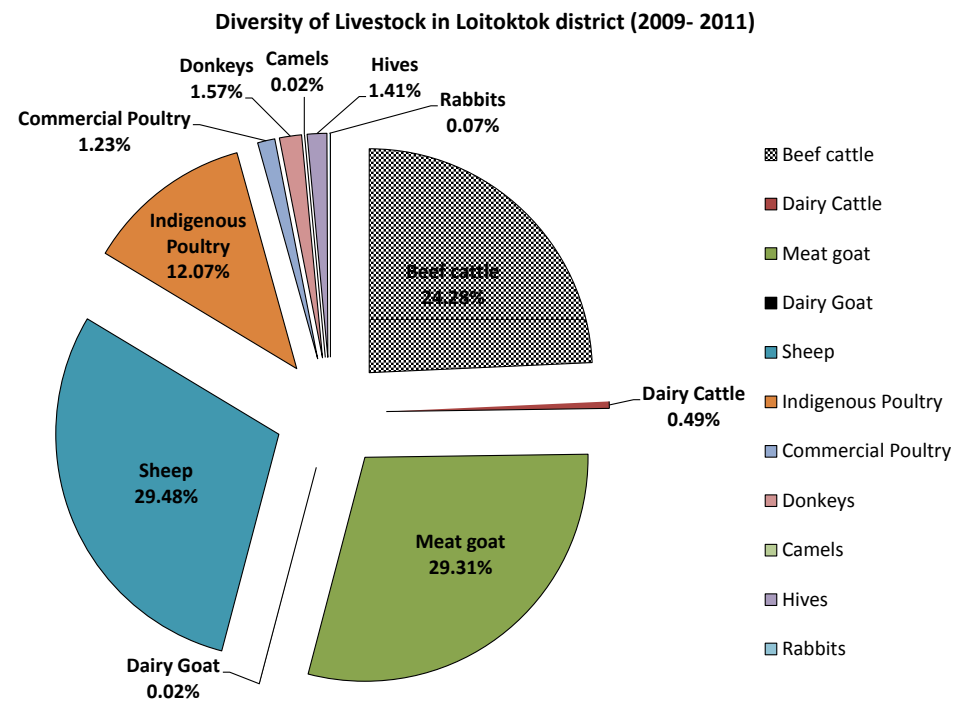

Figure 4. The livestock reared in Loitoktok district. 
gris gallopavo) (386), geese (Chen caerulescens) (238) and ducks (Anas platyrhynchos) (315).

Apart from increasing protein sources in the community, three livestock trends demonstrate how the community is actively strengthening their food security and income generating abilities.

a Camel numbers have increased from 134 in 2009 to 189 in 2011, due to the hardiness and profitability of the species as camel milk and meat consumption is gradually expanding into urban centers. Besides being a source of food, camel-back rides have become popular in entertainment spots or street fairs.

b Increase in dairy goats is driven by the high nutritious value and income generating potential of goat milk especially for $\mathrm{HIV}^{+}$persons.

c Rabbit keeping was introduced to the community in 2011 and has gradually gained prominence because a healthy female doe is able to produce three or four litters per birth, the offspring mature very fast and there is a ready market for the meat and fur that give good incomes to farmers.

The identified reactive adaptation activities were grouped into five main categories to demonstrate community preference (Table 3). Most respondents have adopted new seeds and breeds that are adaptable to drier environmental conditions and subsequently contributed to the high diversity in crops and livestock. Secondly, most respondents agreed that prompt and aggressive actions by the government to curb spread of diseases across land zones and regions have kept epidemics in check. There were numerous training sessions for stakeholders that were carried out by both public and private sectors to equip the community with accurate information for sustained food production. The livestock department had started a communal project to rehabilitate overgrazed areas and hay storage for the community to reduce livestock deaths during droughts. The community was also being taught about modern irrigation technology whereby the drip technique is being promoted against the previously popular open canal practise.

However, respondents stated that low finances (50\%) and low manpower (45\%) hindered arrangement of frequent practical training sessions. Less than 15 extension-officers are charged with the responsibility of disseminating adaptation information across the entire district. This is a tough assignment because apart from individual farmers and pastoralists, there are over 130 farming groups and 51 livestock keeping groups [25]. Thus more personnel are required to increase knowledge on sustainable practices in the community. Secondly, poor coordination (5\%) between national and local government agencies was cited as an obstacle in transfer of knowledge concerning drought forecasts and related technology.

b) Resource Conflict Resolution

As expected in a region with wildlife, human-wildlife conflicts were the main type of resource conflicts affecting food production especially during the dry season (July-October) (Figure 5). This is because wildlife and livestock stray into farms for fodder or livestock (prey) and to access water (for farms located near rivers). This conflict is fuelled by: a) Cultural-clash between pastoralists, farmers and wildlife keepers that pits conservation against development. b) Lack of government policies on strategy to ensure survival of wildlife during drought episodes and poor compensation packages for crop destruction and livestock death caused by wildlife. The lack of compensation causes high tension between the community and administration that sometimes resulted in targeted revenge killings of wildlife by the community. Other conflict causes-land-use competition and water shortage were viewed as manageable issues under proper policy implementation. Key conflict arbitrators are the

\section{Table 3. Community preference of adaptation strategies towards maintaining food production in Loitoktok district.}

\begin{tabular}{|c|c|c|}
\hline \multicolumn{3}{|c|}{ Crops \& Livestock as food ecosystem services } \\
\hline $\begin{array}{c}\text { Reactive } \\
\text { adaptation measures }\end{array}$ & Practical examples & $\begin{array}{l}\text { Community } \\
\text { preference }\end{array}$ \\
\hline \multirow{3}{*}{$\begin{array}{l}\text { Improved seeds } \\
\text { and breeds including }\end{array}$} & Growing low water requirement crops e.g. Kales, onions, sorghum etc. & \\
\hline & Keeping aridly indigenous livestock e.g. Camels, Galla goats, Dorper sheep, Sahiwal bulls. & $24 \%$ \\
\hline & Increase in horticulture \& fruits production that give consistent income. & \\
\hline \multirow[t]{4}{*}{$\begin{array}{l}\text { Enhanced pest } \\
\text { \& disease control }\end{array}$} & $\begin{array}{l}\text { Epidemic control in livestock i.e. Rift Valley fever, and } \\
\text { East Coast fever that are both climate related }\end{array}$ & $14 \%$ \\
\hline & Frequent training sessions for resource users & $11 \%$ \\
\hline & Pasture reestablishment and hay storage for livestock & $9.7 \%$ \\
\hline & Modern irrigation technology and water harvest & $13 \%$ \\
\hline
\end{tabular}




\section{Resource conflicts and related drivers in Loitoktok}

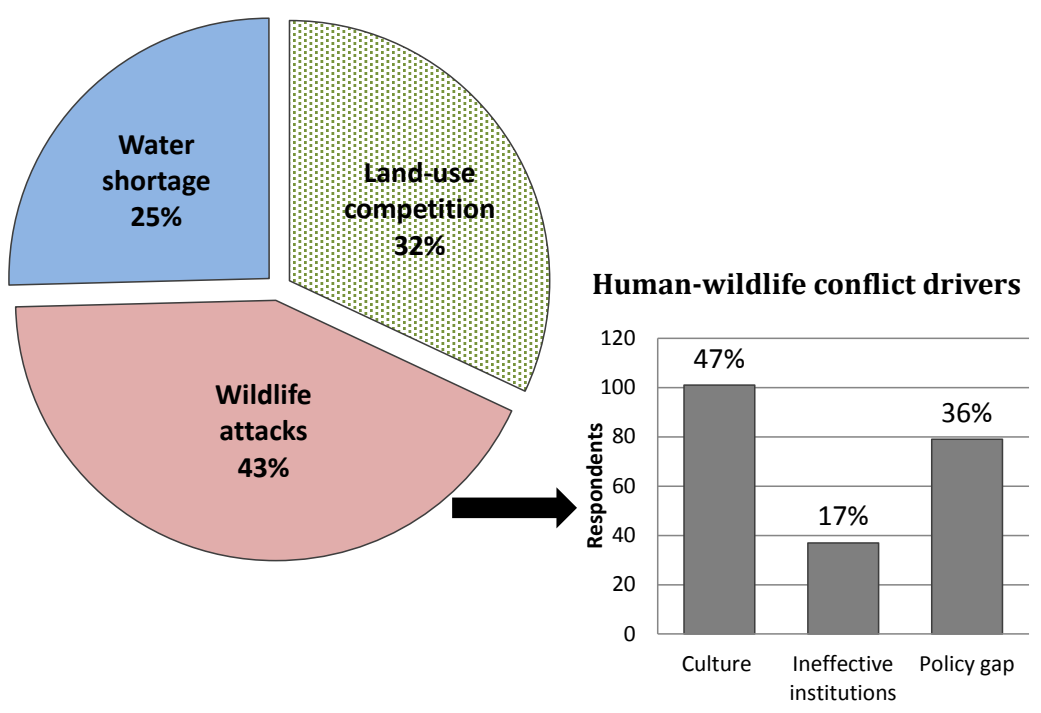

Figure 5. Causes of resource conflicts in Loitoktok. The inset graph reveals additional drivers behind human-wildlife conflicts.

council of elders and government officials who guide negotiations for fair compensation to reduce community tension in Loitoktok.

\subsection{Loitoktok Social Network Structure}

The Loitoktok food production network comprises of 45 actors as illustrated in Figure 6 . To make the network clearer, the 1153 interest groups involved in food production were condensed into five community groups representing women (WGs), youth (YGs), farmers (FG1), pastoralists (PastG1) and self-help groups (SHGs). The network has a centralization score of $57.2 \%$ because it has four main information centers, namely crops (DAO), livestock (DLO), local administration (DLG) and social development (DSdO). This reveals why the community has efficient diverse information circulating between local actors. The calculated network density of 0.66 explains the speed in post-drought recovery and outstanding adaptation activity because network theory states that the closer the density value is to 1, the faster speed at which information diffuses among the nodes.

Since density is influenced by the level of linkage and number of actors in a subgroup, detailed analysis reveals that density differs significantly within the subgroups i.e. crops-0.087, livestock-0.182, conflict resolution0.500 and community-0.333. Thus, though the crop sector has the highest number of actors, it has the lowest density because all links are directed to the extension officers under the District Agricultural office (DAO). On the other hand, conflict resolution sector with the fewest actors has a high density as all actors are interconnected in an efficient local conflict resolution mechanism. This interlinkage explains why the community has few escalated resource conflicts cases and high community cohesion.

The Loitoktok extension officers can be labelled as scale-crossing brokers since they connect two otherwise unconnected actors and "broker" information [19] promoting adoption of new crops or livestock types that enhance ability of the community to respond to climatic changes. More specifically, these brokers are: District Agricultural Office (DAO), District Livestock Office (DLO), District Social Development Office (DSdO), District Local Government (DLG) and District Water Office (DWO) (full names of actors and brokerage values are given in Appendix A). DAO, DLO and DWO connect actors with adaptation knowledge (source) to actors requiring information to boost their productivity and incomes (resource users). While, the DSdO connects the 1153 community groups to local government office (DLG) for accreditation. After accreditation, the community groups link with the Constituency Development Funds offices (CYEDF\& CWEF) for financial support that currently sponsors 71 youth groups and 25 women groups in the district [25]. Since these brokers are all government agencies then network brokerage longevity is assured but a simple change in government policy may cause the Loitoktok network to crumble. 


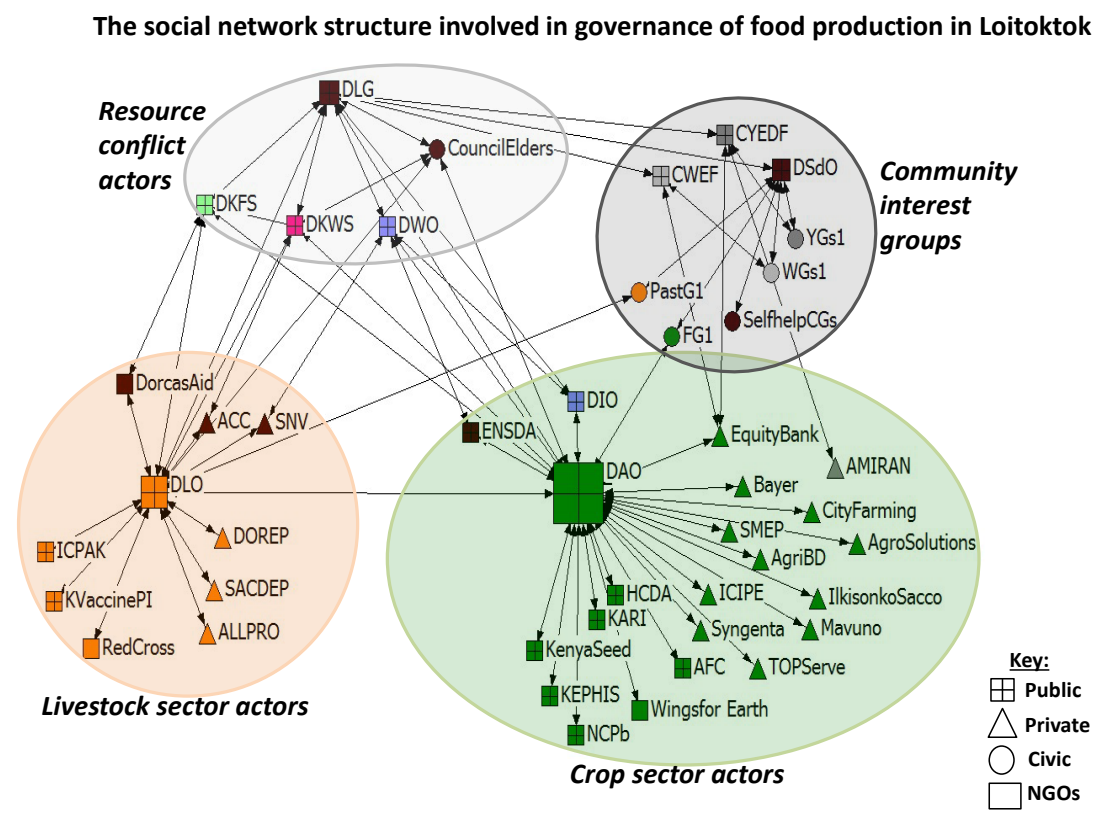

Figure 6. A sociograph of Loitoktok food production sector. The size of the actors was determined using their brokerage values and path distances were used to make the network layout.

\section{Discussion}

The results prove that agricultural production is adapting to climatic changes and that people are actively seeking knowledge to ensure food security and which may be a positive sign that climate-related conflicts may not be part of the projected future of Kenya. Most farmers practise the multiple-cropping system under changing climatic conditions as it reduces the risk of complete crop failure and allows for growing several crops in one growing season. This indigenous agricultural practice is a key reactive adaptation strategy to improve agricultural productivity and food security in rural areas. In addition, the food producer gets to avoid the proverbial "putting eggs in one basket" syndrome and is assured of income even during drought periods. Moreover, this crop diversity benefits natural ecosystems in two main ways, a) adoption of indigenous drought resilient species prevents spread of exotic species that could later become invasive and thus preserve integrity of dryland ecosystems, b) Intercropping with fruit trees could stabilize and enhance soils, contribute to plant biodiversity and provide habitats for a variety of birds, reptiles, small mammals, and insects [1].

\subsection{Evidence of Reactive Adaptation}

The economic component of ESG approach was used to reveal factors that influence adoption of proposed adaptation activities by stakeholders in Loitoktok (Table 4). First adoption factor is yield performance because a farmer wants high crop yields and fast maturing animals that can be sold after a season or in less than a year. Secondly, the crop or livestock (products) must have ready markets and also fetch good prices consistently. This factor originated from the $69 \%$ monetary loss due to questionable grain market dynamics that some Loitoktok farmers suffered despite harvesting sizeable quantities of maize and beans in 2009. In summary, the drought episode was used to formulate some exaggerated food scarcity reports to facilitate subsidized grain import deals under the guise of food insecurity in 2009. These cheap imports diluted prices in local grain markets with direct negative impacts on small scale farmers. Farmers also acknowledge that corruption in the grain sector has influenced their adoption of horticultural and fruit crops that have high demands in urban areas.

\subsection{Source of Reactive Adaptation Knowledge}

The crops and livestock diversity are outcomes of a well-linked and functional social network structure that links extension-officers and external stakeholders with the community in Loitoktok. The high number of exter- 
Table 4. Identified reactive adaptation activities and the respective actors in Loitoktok. This information is also compared against planned adaptation activities by the Kenyan government.

\begin{tabular}{|c|c|c|c|}
\hline \multicolumn{4}{|c|}{ Linkage between actors and their respective adaptation activities sustaining food production in Loitoktok } \\
\hline ESG component & Reactive adaptation measures & Actors-Knowledge brokers & NCCRS planned adaptation \\
\hline \multirow{3}{*}{$\begin{array}{l}\text { Valuation of food } \\
\text { ecosystem services }\end{array}$} & $\begin{array}{l}\text { Low water requirement crops_-kales, } \\
\text { onions, sorghum etc }\end{array}$ & Kenya Seed, NCPB & $\begin{array}{l}\text { Reintroduction of } \\
\text { drought tolerant crops }\end{array}$ \\
\hline & $\begin{array}{l}\text { Aridly indigenous livestock-Camels, } \\
\text { Galla goats, dorper sheep Sahiwal bulls }\end{array}$ & $\begin{array}{c}\text { ACC, Dorcas Aid, DOREP, SACDEP, } \\
\text { ALLPRO }\end{array}$ & $\begin{array}{l}\text { Introduction of } \\
\text { resilient animal breeds }\end{array}$ \\
\hline & $\begin{array}{l}\text { Focus on consistent income generating } \\
\text { foods-horticulture, fruits }\end{array}$ & $\begin{array}{l}\text { HCDA, Equity Bank, AMIRAN, } \\
\text { SMEP, Wings for Earth, AFC }\end{array}$ & \\
\hline \multirow{6}{*}{ Climate adaptation } & $\begin{array}{l}\text { Enhanced epidemic control in Rift } \\
\text { Valley fever, East Coast fever, } \\
\text { Anaplasmosis that are climate related }\end{array}$ & KVaccinePI & $\begin{array}{l}\text { Regular vaccination and } \\
\text { livestock disease surveillance }\end{array}$ \\
\hline & Pest and disease prevention for crops & $\begin{array}{l}\text { TOPServe, Bayer, KEPHIS, } \\
\text { AgroSolutions, City Farming, } \\
\text { Syngenta, ICIPE }\end{array}$ & $\begin{array}{l}\text { Strengthen pest } \\
\text { management systems }\end{array}$ \\
\hline & $\begin{array}{l}\text { Frequent training sessions for resource } \\
\text { users }\end{array}$ & $\begin{array}{l}\text { SNV, ICPAK, AgriBD, } \\
\text { Ilkisonko Sacco, KARI }\end{array}$ & $\begin{array}{l}\text { Enhanced agricultural } \\
\text { extension services }\end{array}$ \\
\hline & Pasture reestablishment and hay storage & GOK & $\begin{array}{l}\text { Widespread fodder } \\
\text { storage programs }\end{array}$ \\
\hline & Soil nutrient management & Mavuno fertilizers, & \\
\hline & Efficient water utilisation & Red Cross (Canal lining), ENSDA & $\begin{array}{l}\text { Build water efficient } \\
\text { irrigation systems }\end{array}$ \\
\hline $\begin{array}{l}\text { Resource conflict } \\
\text { resolution }\end{array}$ & $\begin{array}{l}\text { Intersector negotiations } \\
\text { for fair compensation }\end{array}$ & Council of Elders, DLG & \\
\hline
\end{tabular}

nal (private \& NGOs) actors is the avenue through which the community is able to mobilize multiple adaptation options to solve drought-related production problems (Table 4). A farmer's exposure to information from seed producers, safe agrochemicals and livestock breeders not only enables the farmer to discard unsustainable traditional practices but also to increase his knowledge for additional income generating activities. Hence, this study confirms that rural agricultural practice is not rigid but utilises internal linkages and indigenous knowledge to enhance food security. However, the extension officers who are also the "knowledge brokers" need to be equipped financially and technically for them to effectively circulate accurate adaptation knowledge across rural networks. The network study also revealed that an intricate small committee of actors is responsible for resolving resource conflicts that may lower food production if not handled effectively.

\subsection{Criticism of Planned Adaptation in Kenya}

The Loitoktok community activities encompass most of the proposed planned adaptation activities (Table 4). They have also incorporated three additional site-specific measures that address their challenges, namely:

a) Adoption of food products that give consistent or even high incomes in relation to climatic conditions.

b) Soil nutrient management to enhance food production.

c) An all-inclusive conflict management strategy that builds community cohesion.

If implemented, the planned adaptation strategy seems quite comprehensive in sustaining Kenya's food production against climate change impacts. This is because it also features a unique strategy of developing an inventory of indigenous climate adaptation knowledge as a key adaptation measure. Whereby, projects utilising traditional local knowledge will illuminate potential indigenous adaptation measures that have multiple benefits in terms of diversifying livelihoods to cope with climate stress. The successful projects can then be upscaled to regional or national projects.

However, the listed planned adaptation measures do not differ significantly from a functional agricultural policy that comprises of the basic tenets of smart agriculture (water efficiency, soil and nutrient management, indigenous plants and resilient livestock breeds) that seek increased yields and incomes for its users. This high effort duplication by formulators of NCCRS shows little initiative in addressing core climate change challenges 
facing the country. The Kenyan government through the Climate Change Secretariat estimates that agricultural climate response measures will cost the country \$1.24 m (KES 10.6 b) annually for the entire country [13]. However, these funds should not be used to duplicate ministerial mandates but should instead be used to develop high quality research and information technology products.

For example, lack of reliable weather forecasting technology has resulted in inconsistent production of tomato (Solanumly copersicum) and onion (Allium cepa) in Loitoktok (Figure 7). In 2009, unforeseen drought impacts drastically reduced tomato yields with a $62 \%$ monetary loss for farmers, but onion production unexpectedly surpassed projected yields. Relying on this past drought experience, both tomato and onion acreage was reduced but unpredicted good weather conditions cost the farmers opportunities for bumper harvests in 2010. Subsequently, the loss of opportunity encouraged farmers to increase acreage but a minor unpredicted drought episode reduced yields for tomato farmers though onion farmers got more than their estimated yields in 2011. Such outcomes emphasize importance of research into forecasting technology in the African climate-livelihoods discourse whereby available funds should be directed towards developing efficient early-warning technological applications for mobile phones to prevent such wasted opportunities in the food production sector.

Furthermore, funds from the global adaptation fund can be also be used to implement two planned adaptation measures that seem unattainable at the Kenyan grassroots due to their high financial investment and research commitment. First, insurance against crop failure is a financial product that requires intensive data analysis to justify its introduction and sustainability in the community, but current climate data gaps complicate its implementation. Hence the government can institute large-scale research programs to hasten implementation of these schemes. Similarly, construction of food storage facilities requires high financial capital for construction and maintenance to give affordable quality services to the community. The government can allocate funds to every constituency to construct silos for both food and fodder storage at subsidized costs. These two cases among many others show an urgent need to revaluate the objectives and activities of planned adaptation in Kenya.

\section{Conclusions}

Speculation about the state of food production in sub-Saharan Africa against the impending climate change phenomenon formed the main basis of this study. Results confirm that rural agricultural production is reactively adapting to sustain food production and livelihoods under unreliable climate conditions in Kenya. The rural network structure seems able to empower local food producers with post-drought adaptation knowledge to sustain their incomes and livelihoods. This is achieved through active public-private partnerships (PPP) that target increased agricultural productivity. Actors responsible for the dissemination of reactive adaptation measures are government extension-officers who "broker" adaptation knowledge to ensure that farmers maintain their livelihoods. Thus, regions seeking to enhance post-drought food production should ensure that local stakeholders

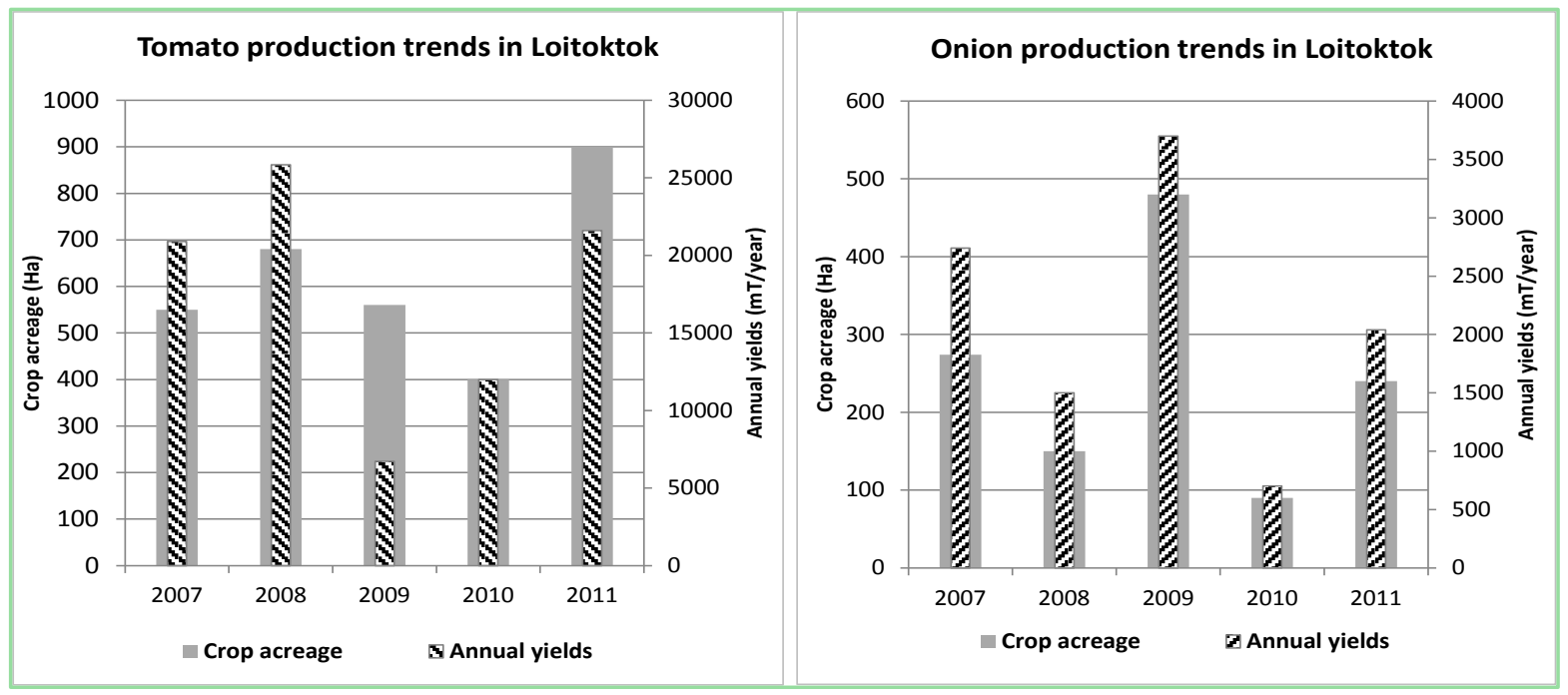

Figure 7. Performance of tomato and onion crops production for 2007-2011 in Loitoktok district. 
from all sectors are interlinked for formulation of a site-specific adaptation strategy that diversifies livelihoods for successful adoption by the community.

This study has also validated the functionality of the newly developed ecosystem service governance approach that seeks to reveal actor responsibilities within a rural community. Evidence of implemented reactive adaptation knowledge is seen in the high diversification of crops and livestock in Loitoktok. These measures include keeping camels, rabbits, and dairy goats; honey production; horticultural and fruit production. In addition, using diverse arid-indigenous species also increases integrity of the natural environment and lessens damage from climate change impacts. Scrutiny into the implemented activities revealed that yield performance and income generation consistency were the key factors influencing post-drought adoption of proposed reactive adaptation measures. Hence there is a need to promote adaptation measures that have these two qualities to enhance their adoption by rural communities seeking consistent income generation. The social network analysis component also revealed the dense connectivity among the conflict resolution actors that has managed to prevent escalation of resource conflicts especially the human-wildlife conflicts prevalent in the area. This active resolution mechanism contradicts the assumption that resource scarcity inevitably leads to violent confrontation among resource users.

On the other hand, critical analysis of planned adaptation revealed effort duplication by the Climate Change Secretariat instead of formulation of specific multitier benefit-projects not addressed by the agriculture sector in Kenya. This study proposes that adaptation funds to be primarily used by the research sector that urgently requires expansion in terms of qualified manpower to train remote rural communities and in construction of more research centres with modern equipment to develop seeds and livestock breeds for the uncertain future.

Finally, though current climate adaptation strategies focus on drought occurrence, many climate-model projections under the $4^{\circ} \mathrm{C}$ warming, indicate that precipitation in East Africa may become wetter than today. This will cause an overall decrease in drought risks but an increased flooding risk due to concentrated precipitation. Therefore, it is also important for stakeholders to begin training rural communities in high water requirement food production techniques such as aquaculture.

\section{Acknowledgements}

Special thanks go to Mr. Benson Ngigi (DAO), Mr. Musili and Dr. Njeru (DLO), and Mr. Kasaini (DLG). This study is a part of a Ph.D. project based at the School of Integrated Climate System Sciences (SICSS) at University of Hamburg, Germany. It is funded by Deutscher Akademischer Austauschdienst (DAAD), National Council for Science and Technology-Kenya (NCST) and Center for a Sustainable University-Hamburg.

\section{References}

[1] Millennium Ecosystem Assessment (2005) Ecosystems and Human Well-Being, Vol. 5. Island Press, Washington DC.

[2] Okello, M.M. and D’amour, D.E. (2008) Agricultural Expansion within Kimana Electric Fences and Implications for Natural Resource Conservation around Amboseli National Park, Kenya. Journal of Arid Environments, 72, 2179-2192. http://dx.doi.org/10.1016/j.jaridenv.2008.07.008

[3] Tubiello, F. (2008) Climate Change Adaptation and Mitigation: Challenges and Opportunities in the Food Sector. Presented at the World Food Security: The Challenges of Climate Change and Bioenergy, Rome, Italy, 29.

[4] Abdou, K., Parker, D.J., Brooks, B., Kalthoff, N. and Lebel, T. (2010) The Diurnal Cycle of Lower Boundary-Layer Wind in the West African Monsoon. Quarterly Journal of the Royal Meteorological Society, 136, 66-76. http://dx.doi.org/10.1002/qj.536

[5] World Bank (2013) Turn down the Heat: Climate Extremes, Regional Impacts, and the Case for Resilience. Potsdam Institute for Climate Impact Research and Climate Analytics, World Bank, Washington DC.

[6] AMCEN (2011) Addressing Climate Change Challenges in Africa: A Practical Guide towards Sustainable Development. African Union Commission \& United Nations Environment Programme Secretariat, Nairobi.

[7] Burke, M.B., Miguel, E., Satyanath, S., Dykema, J.A. and Lobell, D.B. (2009) Warming Increases the Risk of Civil War in Africa. Proceedings of the National Academy of Sciences, 106, 20670-20674. http://dx.doi.org/10.1073/pnas.0907998106

[8] Lobell, D.B., Burke, M.B., Tebaldi, C., Mastrandrea, M.D., Falcon, W.P. and Naylor, R.L. (2008) Prioritizing Climate Change Adaptation Needs for Food Security in 2030. Science, 319, 607-610.

http://dx.doi.org/10.1126/science.1152339 
[9] O’Loughlin, J., Witmer, F.D., Linke, A.M., Laing, A., Gettelman, A. and Dudhia, J. (2012) Climate Variability and Conflict Risk in East Africa, 1990-2009. Proceedings of the National Academy of Sciences, 109, 18344-18349. http://dx.doi.org/10.1073/pnas.1205130109

[10] Müller, C. (2013) African Lessons on Climate Change Risks for Agriculture. Annual Review of Nutrition, 33, 395-411. http://dx.doi.org/10.1146/annurev-nutr-071812-161121

[11] UNFCCC (2007) Climate Change: Impacts, Vulnerabilities and Adaptation in Developing Countries. UN Climate Change Secretariat.

[12] IPCC, Climate Change 2001: Impacts, Adaptation, and Vulnerability: Contribution of Working Group II to the Third Assessment Report of the Intergovernmental Panel on Climate Change. In: McCarthy, J.J., Canziani, O.F., Leary, N.A., Dokken, D.J. and White, K.S., Eds., Cambridge University Press, Cambridge, 2001.

[13] Government of Kenya (2010) National Climate Change Response Strategy. Government Printers, Nairobi.

[14] Handmer, J.W., Dovers, S. and Downing, T.E. (1999) Societal Vulnerability to Climate Change and Variability. Mitigation and Adaptation Strategies for Global Change, 4, 267-281. http://dx.doi.org/10.1023/A:1009611621048

[15] Ngaruiya, G.W. (2014) Ecosystem Service Governance: A Synergistic Approach Developed from Key Natural Management Schemes Relevant in Rural Areas. Accepted for Publication, Ecosyst. Serv.

[16] Government of Kenya (2009) Loitoktok District Development Plan. Office of the Prime Minister, Ministry of Planning National Development and Vision 2030, Nairobi.

[17] Ntiati, P. (2002) Group Ranches Subdivision Study in Loitokitok division of Kajiado District, Kenya. International Livestock Research Institute, Nairobi, Working Paper 7.

[18] Okello, M.M. (2005) Land Use Changes and Human-Wildlife Conflicts in the Amboseli Area, Kenya. Human Dimensions of Wildlife: An International Journal, 10, 19-28. http://dx.doi.org/10.1080/10871200590904851

[19] Ernstson, H., Barthel, S., Andersson, E. and Borgström, S.T. (2010) Scale-Crossing Brokers and Network Governance of Urban Ecosystem Services: The Case of Stockholm. Ecology and Society, 15, 28.

[20] Prell, C., Reed, M., Racin, L. and Hubacek, K. (2010) Competing Structure, Competing Views: The Role of Formal and Informal Social Structures in Shaping Stakeholder Perceptions. Ecology and Society, 15, 34.

[21] Hennig, M., Brandes, U., Pfeffer, J. and Mergel, I. (2012) Studying Social Networks: A Guide to Empirical Research. Campus Verlag.

[22] Bodin, Ö. and Prell, C. (2011) Social Networks and Natural Resource Management: Uncovering the Social Fabric of Environmental Governance. Cambridge University Press, Cambridge. http://dx.doi.org/10.1017/CBO9780511894985

[23] Lin, N. (1999) Social Networks and Status Attainment. Annual Review of Sociology, 25, 467-487. http://dx.doi.org/10.1146/annurev.soc.25.1.467

[24] Borgatti, S.P., Everett, M.G. and Freeman, L.C. (2002) UCINET Software. Analytic Technologies, Harvard.

[25] Ngaruiya, G.W. and Scheffran, J. (2013) Reducing Climate Adaptation Deficits Using Revolving Fund Network Schemes in Rural Areas of Kenya: Case Study of Loitoktok District. African Journal of Economic and Sustainable Development, 2, 347-362. http://dx.doi.org/10.1504/AJESD.2013.058746 


\section{Appendix A}

Full names of actors identified in the rural social network analysis.

\begin{tabular}{|c|c|c|c|c|}
\hline ID & Name of Actor & Type & Centrality & Brokerage \\
\hline $\mathrm{DAO}$ & District Agricultural office & Public & 61.36 & 677 \\
\hline AgriBD & Agriculture Business Development Ltd. & Private & 2.27 & 0 \\
\hline Kenya Seed & Kenya Seed Company & Public & 2.27 & 0 \\
\hline $\mathrm{NCPb}$ & National Cereals \& Produce board & Public & 2.27 & 0 \\
\hline ENSDA & Ewaso Nyiro South Development Authority & Public & 4.55 & 0 \\
\hline KEPHIS & Kenya Plant Health Inspectorate Service & Public & 2.27 & 0 \\
\hline TOPServe & Top Serve Ltd. Company & Private & 2.27 & 0 \\
\hline Bayer & Bayer Solutions Company & Private & 2.27 & 0 \\
\hline Agro Solutions & Agro-Solutions Ltd. Company & Private & 2.27 & 0 \\
\hline City Farming & City Farming Kenya Limited & Private & 2.27 & 0 \\
\hline Syngenta & Syngenta Company & Private & 2.27 & 0 \\
\hline Equity Bank & Equity Bank Ltd. & Private & 6.82 & 6 \\
\hline Mavuno & Mavuno Ltd. Company & Private & 2.27 & 0 \\
\hline SMEP & Small \&Micro Enterprise Program & Private & 2.27 & 0 \\
\hline Ilkisonko Sacco & Ilkisonko Sacco & Civic & 2.27 & 0 \\
\hline AFC & Agricultural Finance Corporation & Public & 2.27 & 0 \\
\hline DLO & District Livestock Office & Public & 34.09 & 189 \\
\hline DorcasAid & Dorcas Aid & NGO & 4.55 & 0 \\
\hline DOREP & Desert Oasis Residents Empowerment Program & Private & 2.27 & 0 \\
\hline SNV & Netherlands Development Organisation & Private & 4.55 & 2 \\
\hline RedCross & Red Cross Ltd. & NGO & 2.27 & 0 \\
\hline ICPAK & $\begin{array}{l}\text { Intergovernmental Panel on Climate } \\
\text { Prediction and Adaptation Kenya }\end{array}$ & Public & 2.27 & 0 \\
\hline SACDEP & Sustainable Agriculture Community Development Programmes & Private & 2.27 & 0 \\
\hline ALLPRO & ASAL-Based Livestock and Rural Development Org. & Private & 2.27 & 0 \\
\hline KVaccinePI & Kenya Vaccine Production Institute & Public & 2.27 & 0 \\
\hline FG1 & Farmer Groups & Civic & 4.55 & 2 \\
\hline PastG1 & Pastoralist Groups & Civic & 4.55 & 2 \\
\hline DKWS & District Kenya Wildlife Service office & Public & 13.64 & 8 \\
\hline DKFS & District Kenya Forest Service office & Public & 11.36 & 5 \\
\hline Council Elders & Council of Elders & Civic & 9.09 & 0 \\
\hline ACC & African Conservation Centre & Private & 4.55 & 0 \\
\hline DWO & District Water Office & Public & 11.36 & 12 \\
\hline DIO & District Irrigation Office & Public & 6.82 & 0 \\
\hline DSdO & District Social Development Office & Public & 13.64 & 30 \\
\hline
\end{tabular}




\section{Continued}

\begin{tabular}{|c|c|c|c|c|}
\hline CYEDF & Constituency Youth Enterprise Development Fund office & Public & 9.09 & 12 \\
\hline YGs1 & Youth Groups & Civic & 4.55 & 2 \\
\hline CWEF & Constituency Women Enterprise Fund office & Public & 6.82 & 6 \\
\hline WGs1 & Women Groups & Civic & 4.55 & 2 \\
\hline SelfhelpCGs & Self-help Groups & Civic & 2.27 & 0 \\
\hline DLG & District Local Government office & Public & 22.73 & 67 \\
\hline KARI & Kenya Agricultural Research Institute & Public & 2.27 & 0 \\
\hline HCDA & Horticultural Crops Development Authority & Public & 2.27 & 0 \\
\hline Wings for Earth & Wings for Earth & NGO & 2.27 & 0 \\
\hline ICIPE & International Centre of Insect Physiology and Ecology & Private & 2.27 & 0 \\
\hline AMIRAN & Amiran Kenya Ltd. & Private & 2.27 & 0 \\
\hline
\end{tabular}


Scientific Research Publishing (SCIRP) is one of the largest Open Access journal publishers. It is currently publishing more than 200 open access, online, peer-reviewed journals covering a wide range of academic disciplines. SCIRP serves the worldwide academic communities and contributes to the progress and application of science with its publication.

Other selected journals from SCIRP are listed as below. Submit your manuscript to us via either submit@scirp.org or Online Submission Portal.
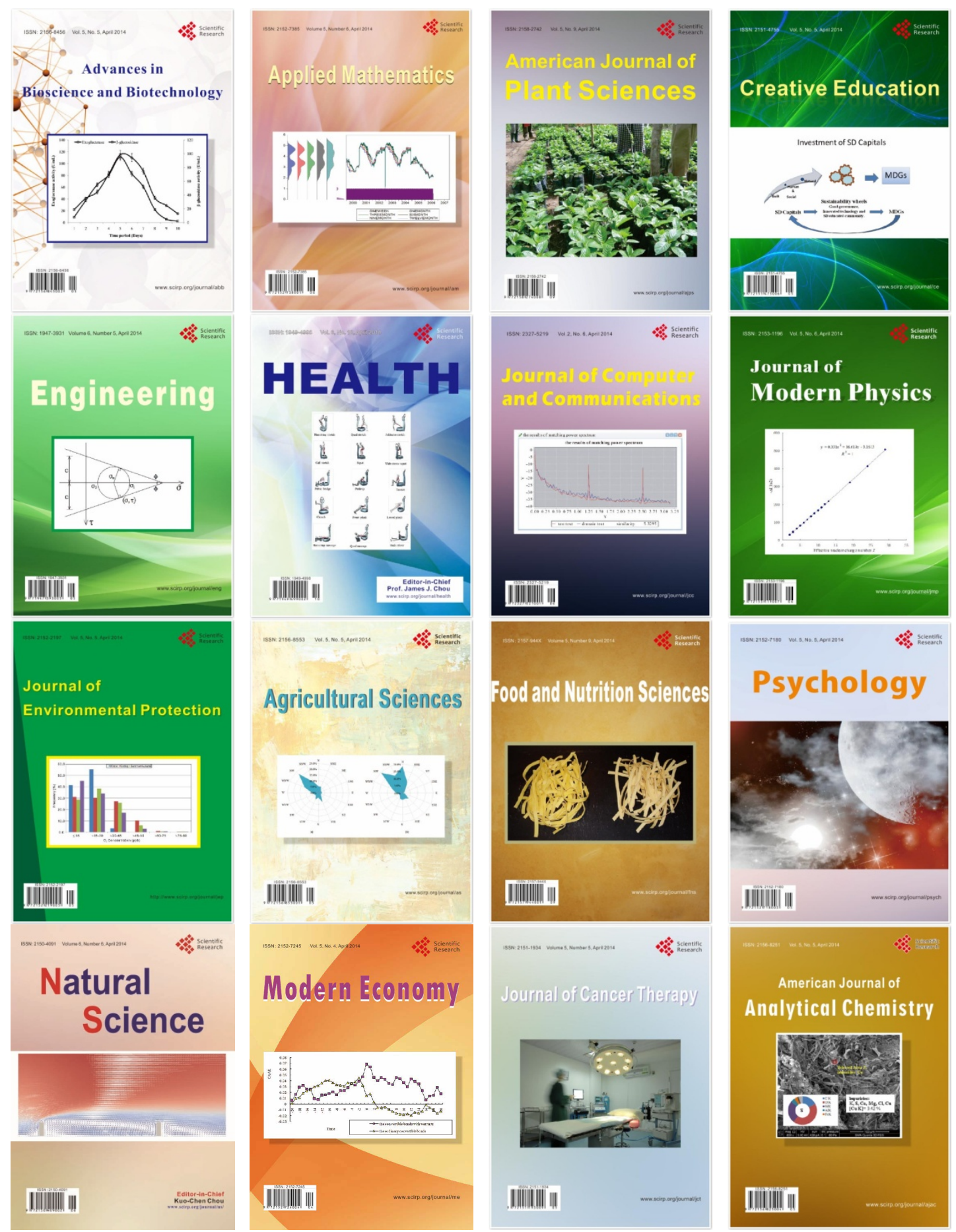